\title{
OPTIMAL ALLOCATION OF TRADABLE EMISSION PERMITS UNDER UPSTREAM-DOWNSTREAM STRATEGIC INTERACTION
}

\author{
GIUSEPPE DE FEO ${ }^{1}$; JOANA RESENDE ${ }^{2}$; MARIA-EUGENIA SANIN ${ }^{3}$
}

\begin{abstract}
Version:
In this paper we analyze environmental regulation based on tradable emission permits in the presence of strategic interaction in an output market with differentiated products. We characterize firms' equilibrium behavior in the permits and in the output market and we show that both firms adopt "rival's cost-rising strategies". Then, we study the problem of the regulator that aims to maximize social welfare, proposing an efficient criterion to allocate permits between firms. We find that the optimal allocation criterion requires a perfect balance between the difference on firms' price-cost margins in the permits and the difference on firms' mark ups in the output market. In light of the previous result, we use a simulation to obtain the optimal allocation of permits between firms as a function of output market characteristics, in particular as a function of goods substitutability.
\end{abstract}

\section{INTRODUCTION}

The interplay between some of the tradable emission permits (TEP) markets implemented so far and the corresponding output market has raised some concern regarding non-competitive emission trading (see Montero, 2009 for a survey on the existing literature on this point). For example, according to Kolstad and Wolak (2008), the oligopolistic firms participating in the Californian electricity market (CAISO) behaved strategically in the Los Angeles market for NOx emissions called RECLAIM (Regional Clean Air Incentives Market). Such firms, shown to exert unilateral market power in the CAISO by Wolak (2003), were allocated $56 \%$ of total initial stock of permits. In the same line, Chen et al. (2006) compute equilibrium behavior considering the interaction between the NOx budget program and the Pennsylvania-New Jersey-Maryland (PJM) electricity market. Due to the high concentration of the PJM market, six large electricity generators alone account for $90 \%$ of emissions in the referred permits market. In this context, Chen et al. (2006)

\footnotetext{
${ }^{1}$ University of Strathclyde and Università degli Studi di Pavia. E-mail: giuseppe.defeo@strath.ac.uk. The authors thank Rabah Amir, Paul Belleflamme, Thierry Brechet, Sofia Castro, Jean Gabszewicz, the Editors Ariel Dinar and Fioravante Patrone, and two anonymous referee report for their helpful comments. The usual disclaimer applies.

${ }^{2}$ University of Porto and Cef.up. E-mail: jresende@fep.up.pt. Financial support from FCT is deeply acknowledged (Research grant PTDC/EGE-ECO/115625/2009).

${ }^{3}$ University of Montpellier 1, UMR5474 LAMETA, and Ecole Polytechnique, Paris, France. E-mail: mariaeugenia.sanin@polytechnique.edu
} 
find that a Stackelberg leader with a long position in the permits market could gain substantial profits by withholding permits and driving up permits costs for rival producers. More recently, Tanaka and Chen (2012) analyze the influence of permits allocation on strategic firms in a forward electricity market that could produce shifts in the spot electricity market. In particular they find that the more allowances are allocated to the less polluting firm, the more this firm will contract in the forward market leading to a decline in spot electricity prices.

Supporters of environmental regulation based on TEP markets argue that the creation of such market makes it possible to reach the pollution reduction target (reflected in "the cap") in a costeffective manner (Montgomery, 1972) and with a minimum information cost for the regulator, in particular concerning the pollution abatement technology available. This argument has been challenged, first, by Hahn's (1984) dominant-fringe model which argues that the existence of market power reduces the cost-effectiveness of TEP markets because a dominant firm manipulates the price of permits to reduce its own emission abatement costs.

Misiolek and Elder (1989), inspired in Salop and Scheffman (1987), and Eshel (2005), also relying on a dominant-fringe setting, show that technological linkages between permits and output markets would give raise to "rival's cost-rising strategies" by the dominant firm, which would introduce an additional type of market distortion. Fehr (1993) and Sartzetakis (1997) have also challenged the effectiveness of environmental regulation based on TEP markets, showing that, in a context of strategic permits trading, TEP markets could lead to monopolization or excessive entry barriers. Although the last two papers have considered strategic interaction in the output market, their objective is to focus on the monopolization or no-entry corner solutions instead of assessing the effects of strategic interaction on optimal permits allocation. In fact, Fehr (1993) assumes that downstream firms buy permits for a given supply, whereas Sartzetakis (1997) assumes a competitive permits market. To our knowledge only Tanaka and Chen (2012) and De Feo et al. (2012) consider a model of strategic interaction both in the permits and in an output market. The former is mostly interested on the way electricity prices are affected by the linkages between a forward electricity market and the permits and spot electricity markets, while the latter is only interested on the way interaction on the permits market impacts the final price in a homogeneous good market.

The main contribution of this paper is to show the dependence of TEP market effectiveness on the way firms' interaction in the output market takes place. We assume that two asymmetric (in terms of production and abatement technology) Cournot producers of a differentiated polluting good also meet in a TEP market where they trade permits that were freely allocated to them. With this purpose we generalize De Feo et al (2012)'s game to the case generic of price competition in a differentiated output market with general demand and abatement functions. The former find that the leader in the permits market always marks-up the price of permits to increase its market share in the output market. Differently from the previous, herein we pin down a full characterization of firms' strategies as a function of their relative (production and abatement) efficiency as well as the 
degree of output differentiation. In this context the price-making firm in the permits market may mark permits up or down. Differently from De Feo et al. (2012) we find a price-making firm in the permits market may set a discount on the permits price if he is a net buyer. This occurs when the degree of differentiation in the output market is enough high. Moreover, even when he is a net seller, the strength of his cost-rising strategies depends on his relative efficiency as compared to his rival.

In light of these results, we show how the net impact of the simultaneous adoption of rival's cost-rising strategies on cost-effectiveness of environmental regulation depends on firms' position in the permits market (buyer or seller), on the interplay of firms' cost structures and on the degree of substitutability between goods. Altogether, these factors determine the way TEP should be allocated to promote efficiency.

In this line, we propose an optimal criterion to allocate permits between firms, when the regulator aims to maximize total welfare. We find that the optimal allocation criterion is the one guaranteeing that the difference on each firm's price-cost margins in the permits and in the output market are equalized for the last permit distributed. Accordingly, the optimal criterion we derive (accounting for strategic interaction in the output market) departs from the so-called equimarginal principle that has been generally adopted by the environmental literature (see for example Requate, 2005). The equimarginal abatement costs criterion assumes perfect competition in the market that is subject to the environmental regulation. While, under perfect competition in the output market equimarginality ensures the minimization of total abatement costs and, consequently, maximization of total welfare, that is not the case in our set-up.

\section{MODELLING FRAMEWORK}

We model firms interaction in the permits market and sequentiality of decisions as in De Feo et al. (2012) but accounting for general demand and abatement functions as well as a differentiated output market. We consider two firms that meet both in the permits and in the output market. In the permits market, one of the firms (say firm $j$ ) is assumed to move first, setting the price of permits and clearing the permits market. In the output market the two firms (firm $i$ and firm $j$ ) compete in quantities producing imperfect substitute goods. Quantity $y_{k}$ represents the production of good $k=i, j$ and $p_{k}$ represents its price. The inverse demand function for each available variant $k$ of the good is given by $p_{k}\left(y_{k}, y_{-k}\right)$, where $y_{-k}$ represents the output production of firm $k^{\prime} s$ rival.

Firms may have asymmetric production technologies. The production cost function of firm $k$ is given by $c_{k}\left[y_{k}\right]$, with $c_{k}^{\prime}\left[y_{k}\right]>0$ and $c_{k}^{\prime \prime}\left[y_{k}\right] \geq 0 .^{4}$

The production of goods $i$ and $j$ generates polluting emissions as a by-product. The parameter $\beta>0$ represents output polluting intensity. We consider that firms must comply with environmental

\footnotetext{
${ }^{4}$ The assumption of non-decreasing marginal production costs has also been used in other papers studying upstream-downstream interactions in TEP markets (see for example, Eshel 2005).
} 
regulation based on a cap and trade system: (i) permits are freely distributed up to the cap $S$ and; (ii) each firm $k$ needs to hold an amount of permits equal to the non-abated polluting emissions generated by the production of $y_{k}$. A percentage $\alpha$ of total permits is received by firm $i$ and a percentage $1-\alpha$ by firm $j$. The parameter $\alpha \in[0,1]$ and the cap $S$ are an exogenous choice of the regulator. In this paper we restrict our attention to the allocation decision (as pointed out by Eshel (2005) the regulator's choices concerning permits allocation and the cap on total permits can be studied separately). ${ }^{5}$

When firms initial permits holdings, $\alpha S$ and $(1-\alpha) S$, respectively, do not coincide with the polluting emissions caused by the production of the optimal quantity of output $\beta y_{k}^{*}$, firms may either abate some of the extra polluting emissions or engage in permits trading. Then, the environmental regulation implies the following restriction:

$$
\beta y_{k}=E_{k}+a_{k}, k=i, j
$$

where $E_{k} \geq 0$ denotes the amount of TEP that firm $k$ must hold to comply with the environmental rule and $a_{k} \geq 0$ stands for the level of emissions abated. The abatement of polluting emissions is costly. Firms may have asymmetric abatement technologies. More precisely, to abate $a_{k}$ polluting emissions, firm $k$ incurs a cost of $h_{k}\left(a_{k}\right),{ }^{6}$ with $h_{k}^{\prime}\left(a_{k}\right)>0$ and $h_{k}^{\prime \prime}\left(a_{k}\right)>0 .{ }^{7}$

Under the previous assumptions, firms' profits write as follows:

$$
\begin{gathered}
\Pi_{i}\left(y_{i}, y_{j}, E_{i}, q\right)=p_{i}\left(y_{i}, y_{j}\right) y_{i}-c_{i}\left(y_{i}\right)+q\left(\alpha S-E_{i}\right)-h\left(\beta y_{i}-E_{i}\right) \\
\Pi_{j}\left(y_{i}, y_{j}, E_{i}, q\right)=p_{j}\left(y_{i}, y_{j}\right) y_{j}-c_{j}\left(y_{j}\right)-q\left(\alpha S-E_{i}\right)-h\left(\beta y_{j}+S-E_{i}\right) .
\end{gathered}
$$

where $(i) \alpha S-E_{i}=x_{i}=-x_{j}$ corresponds to the amount of permits sold (or bought, when $x_{i}<0$ ) by firm $i$; (ii) $\beta y_{i}-E_{i}=a_{i}$ corresponds to the amount of polluting emissions abated by firm $i$ and (iii) $\beta y_{j}-S+E_{i}=a_{j}$ corresponds to the amount of polluting emissions abated ${ }^{8}$ by firm $j$.

Assumption: Throughout the paper we assume that:

(A1) The demand functions are linear with $\frac{\partial p_{k}\left(y_{k}, y_{-k}\right)}{\partial y_{k}}<0$.

(A2) The goods are imperfect substitutes with $\frac{\partial p_{k}\left(y_{k}, y_{-k}\right)}{\partial y_{-k}}<0$.

\footnotetext{
${ }^{5}$ The cap on pollution is generally fixed by the regulatory authority with the help of experts in the light of the pollution control target (e.g. the IPCC 1990 Scientific Assessment in the case of the Kyoto protocol and its European side agreement for the creation of the EU-ETS).

${ }^{6}$ Similarly to Eshel (2005) and De Feo et al. (2012), this paper assumes total cost independence between production and abatement. Since we are interested in analyzing the demand-side mechanisms leading to rival's rising cost strategies, the study of cost dependence between output production and abatement is beyond the scope of this paper.

${ }^{7}$ The assumption of strictly increasing marginal abatement costs is in line with other papers studying TEP markets, such as Montero (2009) and Liski and Montero (2011).

${ }^{8}$ From the market clearing condition, $x_{i}=-x_{j}$. Since $x_{i}=\alpha S-E_{i}$ and $x_{j}=(1-\alpha) S-E_{j}$, we obtain that $E_{i}+E_{j}=S$ and, therefore, $a_{j}=\beta y_{j}-E_{j}$ can be written as $a_{j}=\beta y_{j}-S+E_{i}$.
} 
(A3) $\frac{\partial^{2} \Pi_{k}}{\partial y_{k} \partial y_{-k}}>\frac{\partial^{2} \Pi_{k}}{\partial y_{k}^{2}}$, or:

$$
\frac{\partial p_{k}\left(y_{k}, y_{-k}\right)}{\partial y_{-k}}>2 \frac{\partial p_{k}\left(y_{k}, y_{-k}\right)}{\partial y_{k}}-c_{k}^{\prime \prime}\left(y_{k}\right)-\beta^{2} h_{k}^{\prime \prime}\left(\beta y_{k}-E_{k}\right)
$$

Note that Assumption (A2) implies $\frac{\partial^{2} \Pi_{k}}{\partial y_{k} \partial y_{-k}}=\frac{\partial p_{k}\left(y_{k}, y_{-k}\right)}{\partial y_{-k}}$, which ensures strategic substitutability, i.e. downward sloping reaction functions in the output market. Additionally, (A3) ensures that the equilibrium in the output market is unique. ${ }^{9}$ A sufficient condition when production and abatement costs are convex is that $\frac{\partial p_{k}\left(y_{k}, y_{-k}\right)}{\partial y_{k}}<\frac{\partial p_{k}\left(y_{k}, y_{-k}\right)}{\partial y_{-k}}$.

Under the previous assumptions, we model interaction in the output (downstream) and the permits (upstream) market using a three stages sequential game. The players are the two firms and the timing of the game is the following: in the first stage, firm $j$ sets the price of permits $\left(q \in \mathbb{R}^{+}\right)$; in the second stage, firm $i$ observes the price $q$ and it chooses the amount of permits to use for production $\left(E_{i} \in \mathbb{R}^{+}\right)$, which determines the amount of permits to buy or sell $\left(x_{i} \in \mathbb{R}\right)$. Firm $j$ clears the permits market. Finally, in the third stage, given firms' permits holdings after trading $\left(E_{i} \in \mathbb{R}^{+}\right)$, firms simultaneously interact in the output market, strategically competing on quantities $\left(y_{i} \in \mathbb{R}^{+}\right.$and $\left.y_{j} \in \mathbb{R}^{+}\right)$and abating the extra polluting emissions $\left(a_{k} \in \mathbb{R}^{+}\right.$, with $\left.a_{k}=\beta y_{k}-E_{k}\right)$. The payoffs of the game are the sum of firms' profits in the permits market and in the output market. We rely on the notion of subgame perfect Nash equilibrium (SPNE) to investigate firms' optimal behavior in the context of our sequential game. In the following subsection, we look for the SPNE, using backward induction techniques.

\subsection{Subgame Perfect Nash Equilibrium}

We sequentially solve the three-stages game previously described, starting from the last stage of interaction. In the last stage, both firms simultaneously choose the output levels that solve the following profit maximization problem:

$$
\max _{y_{k} \geq 0} \Pi_{k}\left(y_{k}, y_{-k}, E_{i}, q\right)
$$

where each firm takes as given the output level of the rival firm (in the spirit of Cournot competition) as well as the outcomes in the permits market (to be determined in the first two stages of the game).

The solution ${ }^{10}$ to the previous problem defines firm $k$ 's best response function in the output

\footnotetext{
${ }^{9}$ More precisely it ensures that the downward sloping reaction functions are contractions; i.e., their slope is always smaller than 1 in absolute value.

${ }^{10}$ The Cournot equilibrium is interior as long as the marginal revenue is higher than the marginal cost when $y_{k}=0$. When this is not the case, equilibrium outcomes may correspond to corner solutions, in which firms' optimal behavior may differ from the first order conditions derived in this paper. A sufficient condition to guarantee that we are in an interior solution is to assume that $p_{k}\left[0, y_{-k}\right]>c_{k}^{\prime}[0]+\beta h_{k}^{\prime}[0] \forall y_{-k}$.
} 
market, $k=i, j$ and is directly obtained from the first order condition (FOC):

$$
p_{k}\left(y_{k}, y_{-k}\right)+\frac{\partial p_{k}\left(y_{k}, y_{-k}\right)}{\partial y_{k}} y_{k}=c_{k}^{\prime}\left(y_{k}\right)+\beta h_{k}^{\prime}\left(a_{k}\right)
$$

The equilibrium output levels in the third stage are the quantities for which both firms are giving their best response to the rival's output choice. In other words, the equilibrium vector $\left(y_{i}^{*}\left(E_{i}, q\right), y_{j}^{*}\left(E_{i}, q\right)\right)$ corresponds to the solution of the two-equations system that is obtained when we set $k=i$ and $k=j$ in condition (1).

Condition (1) shows that, in equilibrium each firm chooses the output level $y_{k}^{*}\left(E_{i}, q\right)$ for which there is a perfect balance between the marginal revenue and the marginal cost (including abatement marginal costs). It also illustrates firms' ability to exploit the upstream-downstream strategic linkages to pass-through to consumers (at least part of) the additional cost of environmental regulation. ${ }^{11}$

In the following Lemma, we summarize how the outcomes in the permits market affect output decisions via marginal abatement costs:

Lemma 1. The larger the amount of permits used for production by firm $k$, the larger its equilibrium output level and the lower the equilibrium output level for its rival $-k$. It follows:

$$
\frac{\partial y_{k}^{*}\left(E_{k}\right)}{\partial E_{k}}>0 ; \frac{\partial y_{-k}^{*}\left(E_{k}\right)}{\partial E_{k}}<0
$$

Proof. The proof relies on the study of the cross-partial derivatives $\frac{\partial^{2} \Pi_{k}}{\partial y_{k} \partial E_{k}}$ and $\frac{\partial^{2} \Pi_{-k}}{\partial y_{-k} \partial E_{k}}$ (supermodularity and complementarity, see Amir, 2005). Without loss of generality, suppose $k=i$. Since

$$
\frac{\partial^{2} \Pi_{i}}{\partial y_{i} \partial E_{i}}=\beta h_{i}^{\prime \prime}\left(\beta y_{i}-E_{i}\right)>0
$$

and

$$
\frac{\partial^{2} \Pi_{j}}{\partial y_{j} \partial E_{i}}=-\beta h_{j}^{\prime \prime}\left(\beta y_{j}-S+E_{i}\right)<0
$$

the larger $E_{i}$, the larger $y_{i}^{*}\left(E_{i}\right)$ and the smaller $y_{j}^{*}\left(E_{i}\right)$. ।

Lemma 1 shows that firms' equilibrium output production increases with their level of permits holdings after trading (decreasing with the rival's level). Everything else the same, the larger the amount of permits hold by firm $k$ after trading, the lower its abatement needs. As a result, firm $k^{\prime}$ 's marginal abatement cost is lower and firm $k$ is able to increase its output production. This direct effect is reinforced by the strategic substitutability of firms' output decisions. Accordingly, the result in (2) is independent of which of the two rival firms is the most efficient in terms of

\footnotetext{
${ }^{11}$ The extent to which firms are able to pass-through the environmental costs to consumers has been widely discussed in the context of the debate about windfall profits in oligopolies subject to environmental regulation based on TEP.
} 
abatement.

In the second stage, firm $i$ chooses the amount of permits to use in production $\left(E_{i}\right)$ after observing the price of permits $(q)$. When deciding $E_{i}$, firm $i$ anticipates the strategic interaction that will take place in the output market. Formally, firm $i$ solves the following optimization problem:

$$
\begin{aligned}
& \max _{E_{i} \geq 0} \Pi_{i}\left(y_{i}, y_{j}, E_{i}, q\right) \\
& \text { s.t. } y_{i}=y_{i}^{*}\left(E_{i}\right) \text { and } y_{j}=y_{j}^{*}\left(E_{i}\right)
\end{aligned}
$$

The restrictions follows from firm $i^{\prime}$ s ability to anticipate how its decisions in the permits market affect output competition in the third stage.

The solution to the previous problem defines firm $i$ 's equilibrium permits endowments after trading conditional on the price of permits, $E_{i}^{*}(q)$. In the interior equilibrium, $E_{i}^{*}(q)$ is obtained from the FOC of the previous problem, that after rearranging ${ }^{12}$ becomes

$$
q-h_{i}^{\prime}\left(y_{i}^{*}\left(E_{i}\right)\right)=\frac{\partial p_{i}\left(y_{i}^{*}, y_{j}^{*}\right)}{\partial y_{j}^{*}} y_{i}^{*} \frac{\partial y_{j}^{*}\left(E_{i}\right)}{\partial E_{i}}
$$

In equilibrium, $E_{i}^{*}(q)$ is such that firm $i$ does not have any opportunity to increase its total profits by trading-off output profits by profits due to permits' transactions. ${ }^{13}$ The equilibrium condition (3) shows that, when deciding $E_{i}$, firm $i$ takes into account the marginal profitability of permits transactions $\left(q-h_{i}^{\prime}().\right)$ as well as the impact of $E_{i}$ in the profits in the output market (which is given by the LHS of (3)). This behavior leads firm $i$ to adopt a "rival's cost-rising strategy". Despite being a follower in the permits market, firm $i$ does not behave as a typical price-taker. Differently from the dominant-fringe setting (e.g. Eshel 2005), in the context of our model, firm $i$ has incentives to over-use emission permits to decrease its abatement needs (while increasing the rival's abatement needs) and become more competitive in the output market.

The following Lemma demonstrates that firm i's behavior in the permits market is indeed consistent with a rival's cost-rising strategy. ${ }^{14}$

Lemma 2. For a given price of permits $q$, firm $i$ abates less than efficiently. The difference

${ }^{12}$ The FOC is

$$
\frac{d \Pi_{i}}{d E_{i}}=\frac{\partial \Pi_{i}}{\partial E_{i}}+\frac{\partial \Pi_{i}}{\partial y_{i}^{*}\left(E_{i}\right)} \frac{\partial y_{i}^{*}\left(E_{i}\right)}{\partial E_{i}}+\frac{\partial \Pi_{i}}{\partial y_{j}^{*}\left(E_{i}\right)} \frac{\partial y_{j}^{*}\left(E_{i}\right)}{\partial E_{i}}=0
$$

Since $\partial \Pi_{i} / \partial y_{i}^{*}\left(E_{i}\right)=0$ because firm $i$ optimally chooses its quantity in the third stage, the FOC reduces to

$$
\frac{\partial \Pi_{i}}{\partial E_{i}}+\frac{\partial \Pi_{i}}{\partial y_{j}^{*}\left(E_{i}\right)} \frac{\partial y_{j}^{*}\left(E_{i}\right)}{\partial E_{i}}=0
$$

where $\frac{\partial \Pi_{i}}{\partial E_{i}}=-q+h_{i}^{\prime}\left(y_{i}^{*}\left(E_{i}\right)\right)$ and $\frac{\partial \Pi_{i}}{\partial y_{j}^{*}\left(E_{i}\right)}=\frac{\partial p_{i}\left(y_{i}^{*}, y_{j}^{*}\right)}{\partial y_{j}^{*}} y_{i}^{*}$.

${ }^{13}$ Our analysis is valid when the second order condition $\frac{d^{2} \Pi_{i}^{*}\left[E_{i}, q\right]}{d E_{i}^{2}}<0$ holds. See Appendix for its explicit computation.

${ }^{14}$ The result in Lemma 2 is in line with the result in the simpler setup of De Feo et al. (2012). 
between permits price and firm i's marginal abatement costs is given by:

$$
q-h_{i}^{\prime}\left(y_{i}^{*}\left(E_{i}\right)\right)=\frac{\partial p_{i}\left(y_{i}^{*}, y_{j}^{*}\right)}{\partial y_{j}^{*}} y_{i}^{*} \frac{\partial y_{j}^{*}\left(E_{i}\right)}{\partial E_{i}}>0
$$

Proof. The proof is straightforward since $\frac{\partial p_{i}\left(y_{i}^{*}, y_{j}^{*}\right)}{\partial y_{j}^{*}}<0$ and $\frac{\partial y_{j}^{*}\left(E_{i}\right)}{\partial E_{i}}<0$, as shown in Lemma 1. I

Due to strategic interaction in the output market, the price-taking firm in the permits market ends up behaving strategically: firm $i$ strategically chooses to forego profits from permits transactions to benefit from a better position in relation to its rival in the output market. Differently from a typical price-taker, firm $i$ uses its decisions concerning $E_{i}$ to reduce its overall marginal costs, while increasing its rival marginal costs (recall that the rival is responsible for clearing the permits market). This strategy allows firm $i$ to increase its market share in the output market, obtaining higher output profits than the profit level corresponding to the choice of $E_{i}$ that leads to $q=h_{i}^{\prime}$.

Finally, in the first stage, firm $j$ quotes the price $q^{*}$ that solves the following optimization problem:

$$
\begin{aligned}
& \max _{q \geq 0} \Pi_{j}\left(y_{i}, y_{j}, E_{i}, q\right) \\
& \text { s.t. } E_{i}=E_{i}^{*}(q), y_{i}=y_{i}^{*}\left(E_{i}^{*}(q)\right) \text { and } y_{j}=y_{j}^{*}\left(E_{i}^{*}(q)\right) .
\end{aligned}
$$

Since firm $j$ anticipates interactions in the subsequent stages of the game, we need to account for the previous restrictions that state that firm $j$ is able to anticipate both (i) firm $i^{\prime}$ s permits holdings after trading in the second stage, i.e. $E_{i}=E_{i}^{*}(q)$; and (ii) how the decisions in the permits market affect output competition in the third stage, i.e. $y_{k}=y_{k}^{*}\left(E_{i}^{*}(q)\right), k=i, j$.

Concentrating exclusively on the case of interior solutions, the equilibrium price of permits is obtained from the first order condition to the previous problem $\frac{d \Pi_{j}}{d q}=0$, yielding:

$$
\frac{\partial \Pi_{j}}{\partial q}+\frac{\partial \Pi_{j}}{\partial E_{i}^{*}} \frac{\partial E_{i}^{*}}{\partial q}=-\frac{\partial \Pi_{j}}{\partial y_{j}^{*}} \frac{\partial y_{j}^{*}}{\partial E_{i}^{*}} \frac{\partial E_{i}^{*}}{\partial q}-\frac{\partial \Pi_{j}}{\partial y_{i}^{*}} \frac{\partial y_{i}^{*}}{\partial E_{i}^{*}} \frac{\partial E_{i}^{*}}{\partial q}
$$

The equilibrium price of permits $q^{*}$ that satisfies the previous guarantees that firm $j$ is exploiting all existing profit opportunities (considering the permits market as well as the output market). In equilibrium, variations in output profits induced by marginal variations in $q$ (given by the RHS in condition (5)) are exactly compensated by variations in the profits associated with permits' transactions (given by the LHS in condition (5)). The optimality condition shows that the equilibrium price of permits $q^{*}$ depends on firm $j^{\prime}$ s market power in the permits market but also on firms' ability to exploit the technological linkages between permits and output markets. As a result, the 
equilibrium price of permits will, in general, differ from firm $j^{\prime}$ s marginal abatement cost. ${ }^{15}$ The following Lemma identifies the mechanisms driving firm $j$ away from marginal cost pricing in the permits market.

Lemma 3. Everything else the same, the equilibrium price of permits $\left(q^{*}\right)$ may be either higher or lower than the efficient one, $\widehat{q}=h_{j}^{\prime}$, with:

$$
q-h_{j}^{\prime}=-\frac{\partial p_{j}\left(y_{i}, y_{j}\right)}{\partial y_{i}^{*}} \frac{\partial y_{i}^{*}}{\partial E_{i}^{*}} y_{j}^{*}+\frac{x_{i}^{*}}{\partial E_{i}^{*} / \partial q} .
$$

Proof. Equation 6 is obtained by substituting the single elements in (5) and rearranging. '

The first determinant of the difference between the equilibrium price of permits $q^{*}$ and the marginal abatement cost $h_{j}^{\prime}$ corresponds to the positive term $-\frac{\partial p_{j}\left(y_{i}, y_{j}\right)}{\partial y_{i}} \frac{\partial y_{i}^{*}}{\partial E_{i}} y_{j}^{*}\left(E_{i}(q)\right)>0$ in condition (6). This term is associated with firm $j$ 's reaction to firm $i^{\prime}$ s cost-rising strategy in the second stage. In stage 2 , firm $i$ wishes to purchase more/ sell less permits than a competitive firm would do. This shifts upwards firm $i$ 's demand/ supply of permits. Anticipating such behavior, in the first stage, firm $j$ tries to make firm $i^{\prime}$ s rising-cost strategy less effective by charging an additional mark-up equal to $-\frac{\partial p_{j}\left(y_{i}, y_{j}\right)}{\partial y_{i}} \frac{\partial y_{i}^{*}}{\partial E_{i}} y_{j}^{*}\left(E_{i}(q)\right)>0$.

The second determinant of the gap $q^{*}-h_{j}^{\prime}$ is associated with the market power of firm $j$ in the permits market. This determinant corresponds to $\frac{x_{i}^{*}(q)}{\partial E_{i}^{*}(q) / \partial q}$ in condition (6). Focusing exclusively on this effect, condition (6) implies that, everything else the same, when firm $j$ is a net-seller of permits $\left(x_{i}^{*}<0\right)$, it is willing to quote an additional mark-up ${ }^{16}$ over $h_{j}^{\prime}$. In contrast, when firm $j$ is a net-buyer of permits $\left(x_{i}^{*}>0\right)$, there is a price discount equal to $\frac{x_{i}^{*}(q)}{\partial E_{i}^{*}(q) / \partial q}$.

In light of (6), the gap $q^{*}-h_{j}^{\prime}$ may be positive or negative. When firm $j$ is a seller of permits it will certainly be positive. In contrast, when firm $j$ is a buyer of permits, if the effect $\frac{x_{i}^{*}(q)}{\partial E_{i}^{*}(q) / \partial q}$ is very strong, firm $j$ might be interested in marking down the price of permits in order to increase its profits from permits trading. This possibility is ruled out in De Feo et al. (2012). Due to perfect substitutability, in their paper it is always profitable to mark up the price of permits in an interior solution to become more competitive in the output market. Herein, instead, we see how the degree of output competition (which is related to the degree of product differentiation ${ }^{17}$ ) and abatement

${ }^{15}$ The single elements of equation (5) are the following. On the LHS:

$$
\begin{gathered}
\frac{\partial \Pi_{j}}{\partial q}=E_{i}^{*}-\alpha S=-x_{i}^{*}(q) \\
\frac{\partial \Pi_{j}}{\partial E_{i}^{*}}=q-h_{j}^{\prime}\left(\beta y_{j}-S+E_{i}\right)
\end{gathered}
$$

and $\frac{\partial E_{i}^{*}}{\partial q}<0$ because $\frac{\partial^{2} \Pi_{i}}{\partial E_{i} \partial q}=-1<0$.

On the RHS, we have that $\frac{\partial \Pi_{j}}{\partial y_{j}^{*}} \frac{\partial y_{j}^{*}}{\partial E_{i}^{*}} \frac{\partial E_{i}^{*}}{\partial q}=0$,by the FOC of firm $j$ in the third stage. In addition, $\frac{\partial \Pi_{j}}{\partial y_{i}^{*}}=$ $\frac{\partial p_{j}\left(y_{i}, y_{j}\right)}{\partial y_{i}} y_{j}^{*}<0$; and $\frac{\partial y_{i}^{*}}{\partial E_{i}^{*}}<0$ as shown in Lemma 1 .

${ }^{16}$ Recall that $\frac{\partial E_{i}^{*}(q)}{\partial q}<0$.

${ }^{17}$ Competition is intense when goods are closer substitutes. 
cost asymmetries interact to determine which strategy is more profitable for the firm.

Subtracting (6) from (4) we can compute the equilibrium value of the gap between firms' marginal abatement costs:

$$
h_{i}^{\prime}\left(a_{i}^{*}\right)-h_{j}^{\prime}\left(a_{j}^{*}\right)=\frac{x_{i}^{*}(q)}{\partial E_{i}^{*}(q) / \partial q}-\frac{\partial p_{j}}{\partial y_{i}} \frac{\partial y_{i}^{*}}{\partial E_{i}} y_{j}^{*}-\frac{\partial p_{i}}{\partial y_{j}} \frac{\partial y_{j}^{*}}{\partial E_{i}} y_{i}^{*} .
$$

The previous equality shows that the equilibrium differential between firms' abatement costs can be decomposed in three effects. The first effect is given by $\frac{x_{i}^{*}(q)}{\partial E_{i}^{*}(q) / \partial q}$ and it stems from firm $j^{\prime}$ s market power in the permits market (Hahn, 1985). This effect may be positive or negative (depending on whether firm $i$ is a buyer or a seller of permits, respectively). The second effect is given by $-\frac{\partial p_{j}}{\partial y_{i}} \frac{\partial y_{i}^{*}}{\partial E_{i}} y_{j}^{*}>0$ and it stems from firm $j^{\prime}$ s ability to adopt a rising rival's cost strategy. This effect is equivalent to the output market effect emphasized in the dominant-fringe literature (see, e.g. Eshel, 2005). Finally, the third effect is given by $-\frac{\partial p_{i}}{\partial y_{j}} \frac{\partial y_{j}^{*}}{\partial E_{i}} y_{i}^{*}<0$ and it is associated with firm $i$ 's ability to adopt rising rival's cost strategies as well.

Whether this third effect increases or decreases the gap between marginal abatement costs depends on firms' position in the permits market, as well as on the interplay of firms in the permits market and in the output market ${ }^{18}$.

In the context of our general framework, firms' behavior is influenced by several determinants (demand configuration, production costs, abatement technologies, pollution intensities and regulatory decisions) that affect equilibrium outcomes in potentially different directions. In Appendix B we consider specific functional forms to illustrate the strategic interactions previously discussed. In the remainder of this section, we highlight how the key parameters of our model (namely, pollution intensity, degree of substitutability in the output market, and firms' abatement technologies) affect equilibrium outcomes. We leave the analysis of welfare and regulatory implications for next section.

First, it is worth noting that in this paper we have assumed that the two firms have the same pollution intensity $\beta$, somehow ${ }^{19}$ implying the use of the same production technology by the two firms. Assuming different pollution intensities would be different from assuming differences in

\footnotetext{
${ }^{18}$ When firm $j$ is a net buyer of permits and the first term in the RHS of (6) is higher in absolute value than the second term, permits prices are under-priced, leading to $h_{i}^{\prime}\left(a_{i}^{*}\right)<h_{j}^{\prime}\left(a_{j}^{*}\right)$. The fact that permits are under-priced generate a downward move along firm $i$ 's supply of permits. This is further aggravated by the upward shift in the supply of permits that is associated with firm $i^{\prime}$ s rising rival's cost strategies. When firm $j$ is a net-seller of permits, they are always over-priced $\left(q^{*}>h_{j}^{\prime}\left(a_{j}^{*}\right)\right)$. The higher price of permits induces a reduction in the quantity of permits demanded by firm $i$ due to a move along firm $i^{\prime}$ s demand curve for permits. However, as described in Lemma 2, firm $i^{\prime}$ s strategic behavior also shifts permits' demand curve upwards. As the two effects move in opposite directions, it is not possible to say a priori, which firm has the lowest marginal abatement cost. When $\frac{\partial p_{i}}{\partial y_{j}} \frac{\partial y_{j}^{*}}{\partial E_{i}} y_{i}^{*}$ is small enough, we have that $h_{i}^{\prime}\left(a_{i}^{*}\right)>h_{j}^{\prime}\left(a_{j}^{*}\right)$. In contrast, when the adoption of rising rival's cost strategy by firm $i$ more than compensates firm $j^{\prime}$ s over-pricing strategy in the permits market, we have that firm $i$ is the one with the lowest marginal abatement cost $\left(\right.$ with $\left.h_{i}^{\prime}\left(a_{i}^{*}\right)<h_{j}^{\prime}\left(a_{j}^{*}\right)\right)$.

${ }^{19}$ Somehow because the production technology is given both by the pollution intensity $\beta$, which reflects the use of a polluting input which is the same for both firms, and the separable production $\operatorname{cost} c_{k}\left(y_{k}\right)$.
} 
abatement technologies and cannot be fully captured by using simple scale factors in the abatement function. It is therefore worth discussing what would be the effect of having a firm using a less polluting production process. Everything else the same, a lower $\beta$ would shift outwards the reaction function in the output market of the less polluting firm (and make it flatter). The result would be that the less polluting firm would produce more in equilibrium, for any given amount of permits held, and the most polluting firm would produce less.

As for the permits market, we first explore the case in which firm $i$ has a lower pollution intensity than firm $j$. Looking at equation (4), when comparing the results with firm $i$ having a lower $\beta$ we can identify a direct effect, for which firm $i$ is willing to accept a lower price for the supply of any amount of permits (and is therefore willing to sell more permits for any given price $q$ ): $h_{i}^{\prime}$ decreases with a lower pollution intensity. However there is also a strategic effect which goes in the opposite direction. ${ }^{20}$ In equation (4) the term on the RHS increases with a lower $\beta$ since $y_{i}^{*}$ is larger for any given $E_{i}$. This term shows that the less polluting firm is willing to withhold permits in order to gain a strategic advantage in the output market.

The same reasoning can be done in the case in which firm $j$ has a pollution intensity that is lower than firm $i$. Looking at (6) we see that there is a direct effect of a lower $\beta$ on the demand of permits by firm $j$ that would choose a lower $q$ (and therefore a lower $E_{j}$ ) on the supply schedule of firm $i$ because of its lower marginal abatement cost $h_{j}^{\prime}$. As in the case of firm $i$ there is also a strategic effect related to the rising-rival-cost strategy of firm $j$. The firm with lower $\beta$ has an incentive to withhold pollution permits in order to gain an advantage on the output market. Everything else the same, the term on the RHS of (6) increases with a lower $\beta$ since $y_{j}^{*}$ is larger for any given $E_{i}$.

Regarding the degree of product differentiation in the output market, it affects firms' optimal decisions not only in the output market but also in the permits market. As shown in (4), the degree of substitutability between good i and j determines the magnitude of $\mathrm{q}-\mathrm{h}_{i}^{\prime}$ for firm i. Similarly, the degree of substitutability between good $\mathrm{j}$ and $\mathrm{i}$ determines the magnitude of the first term in (6). When products are very differentiated, a reduction in firms' marginal abatement cost has a lower impact on firms' relative competitiveness in the output market than in the case of close substitutes. Accordingly, when products are significantly differentiated, the rival's cost-rising strategies tend to become less effective and the equilibrium price of permits is mostly influenced by firm $j^{\prime}$ 's position in the permits market. Instead, when products are close substitutes ${ }^{21}$, firms' relative competitiveness in the output market depends more significantly on their marginal abatement cost and therefore firm $j$ tends to mark up the price of permits to decrease its abatement needs (while increasing the rival's abatement needs) and become more competitive in the output market.

The asymmetry between marginal abatement cost functions also affect the relative magnitude of the two effects in (6) and, as we will see in the following section, the optimal allocation of

\footnotetext{
${ }^{20}$ We thank an anonimous referee for pointing out this effect.

${ }^{21}$ This is the case of De Feo et al. (2012) who consider perfectly substitute goods.
} 
permits between firms. As the relative size of the permits market increases in relation to the output market, if firm $j$ is a net buyer of permits, it tends to be more interested in marking-down the price of permits than in increasing its rival's cost in the output market.

\section{REGULATION AND POLICY IMPLICATIONS}

From Lemma 2, we conclude that strategic interaction in the output market results in an upward shift of firm $i^{\prime}$ s demand curve (or supply curve) of permits, which leads firm $i$ to under-invest in pollution abatement, for any given price of permits. Depending on the interplay between the market power in the permits market and the incentive to adopt a rival's cost-rising strategy, firm $j$ might be interested in abating more or less than efficiently.

Environmental literature usually presents the maximization of social welfare as the main objective of the environmental regulator. With this purpose the regulator maximizes welfare that depends positively on consumer's surplus $(C S)$ and profits $\left(\Pi_{i}+\Pi_{j}\right)$ and negatively on a damage function that depends on total emissions, and that herein we assume linear. Since total emissions in a cap-and-trade system are fixed equal to $S$ our linear damage function $a S$ does not depend on the permits allocation rule $\alpha$. Then, the regulator maximizes

$$
W=C S+\Pi_{i}+\Pi_{j}-a S
$$

with respect to $\alpha$ anticipating subsequent equilibrium outcomes, $q^{*}(\alpha), E_{i}^{*}\left(q^{*}(\alpha)\right)$ and $y_{k}^{*}\left(E_{i}^{*}\left(q^{*}(\alpha)\right)\right)$. Accordingly, we consider that the regulator is able to anticipate the impacts of $\alpha$ not only in the permits market but also on the output market. In particular, the regulator is able to anticipate that along the equilibrium path, the output level of the firm receiving more permits increases while the output of the firm receiving less permits decreases (see the Appendix for more detail on this):

$$
\frac{\partial y_{i}^{*}}{\partial \alpha}>0 \text { and } \frac{\partial y_{j}^{*}}{\partial \alpha}<0
$$

The mechanism behind this result is the following: first, an increases of $\alpha$ leads to a decrease in the permits' price. This reduction of the price of permits entails a downward move along firm $i^{\prime}$ s demand curve for permits (or supply of permits, if firm $i$ is a net-seller), which, in turn, leads to an increase in the use of permits for production by firm $i$. As a consequence, firm $i$ 's marginal abatement costs are lower than before, yielding an increase in firm $i^{\prime}$ s output production. The opposite occurs to firm $j$, that looses market share after an increase of $\alpha$. The impact on total output and consumers' welfare depends on whether the increase of $y_{k}$ more than compensates the decrease of $y_{-k}$ after the variation of $\alpha$. 
Give the regulator's maximization problem, the following FOC is valid for interior solutions ${ }^{22}$ :

$$
\frac{\partial C S}{\partial \alpha}+\frac{\partial \Pi_{i}}{\partial \alpha}+\frac{\partial \Pi_{j}}{\partial \alpha}=0
$$

In Appendix $\mathrm{C}$ we show how the previous FOC results in the following optimal permits allocation rule in the case of symmetric demands in the output market:

$$
\frac{d E_{i}^{*}}{d \alpha}\left(h_{i}^{\prime}-h_{j}^{\prime}\right)=\frac{d E_{i}^{*}}{d \alpha}\left(\frac{\partial y_{i}^{*}}{\partial E_{i}} y_{i}^{*} \frac{\partial p_{i}}{\partial y_{i}}+\frac{\partial y_{j}^{*}}{\partial E_{i}} y_{j}^{*} \frac{\partial p_{j}}{\partial y_{j}}\right)
$$

Basically such allocation rule ensures that any asymmetry on firms' equilibrium marginal abatement costs is compensated by an equal asymmetry in the strategic effect on the output market in equilibrium.

The result in (9) violates the so-called equimarginal principle that has been generally adopted by the environmental literature (see for example Requate, 2005) that assumes perfect competition in the market that is subject to the environmental regulation (see for example Montgomery, 1972). Under perfect competition in the output market equimarginality ensures the minimization of total abatement costs and, consequently, maximization of total welfare. Due to the strategic interaction in the output market our result differs from the equimarginal principle. In fact (9) can be reformulated as we do in the following proposition.

Proposition 1. The optimal allocation of permits is the one that ensures that the difference on each firm's price-cost margins in the permits and in the output market are equalized for the last permit distributed:

$$
\left[\left(q-h_{j}^{\prime}\right)-\frac{\partial y_{j}^{*}}{\partial E_{j}} \mu_{j}^{*}\right] \frac{d E_{i}^{*}}{d \alpha}=\left[\left(q-h_{i}^{\prime}\right)-\frac{\partial y_{i}^{*}}{\partial E_{i}} \mu_{i}^{*}\right] \frac{d E_{i}^{*}}{d \alpha}
$$

where we note markups as $\mu_{j}^{*}=\left(p_{j}^{*}-c_{j}^{\prime}-\beta h_{j}^{\prime}\right)$ and $\mu_{i}^{*}=\left(p_{i}^{*}-c_{i}^{\prime}-\beta h_{i}^{\prime}\right)$ respectively.

Proof. See Appendix C. '

From Proposition 1 it follows that the optimal allocation of permits is the one guaranteeing that, for the last permit distributed, the difference on each firm's price-cost margin in the permits market is balanced with the difference on each firm's mark-up in the output market, where the latter is weighted by $\frac{\partial y_{k}^{*}}{\partial E_{k}}$ which measures the effect of the allocation on firm's output production. From (10) we get

$$
h_{i}^{\prime}-h_{j}^{\prime}=\frac{\partial y_{j}^{*}}{\partial E_{j}} \mu_{j}^{*}-\frac{\partial y_{i}^{*}}{\partial E_{i}} \mu_{i}^{*}
$$

\footnotetext{
${ }^{22}$ Our analysis is only valid when the conditions that guarantee the existence of an interior solution exist. In our general setup it is not possible to derive explicitly the conditions that guarantee that an interior solution exists. Whenerver existence conditions for an interior solution are violated, a corner solution arises and the regulator must allocate all the available emission permits to only one of the firms.
} 
The gap in marginal abatement costs must compensate for the relative strength of firms' strategic effects in the output market. For each firm $k$, the strategic effect is captured by $\frac{\partial y_{k}^{*}}{\partial E_{k}} \mu_{k}^{*}$, which measures the marginal profitability obtained by firm $k$ in the output market when it uses an additional permit in production. When firm $j^{\prime}$ s strategic effect $\frac{\partial y_{j}^{*}}{\partial E_{j}} \mu_{j}^{*}>0$ is higher than the one of firm $i$, given by $\frac{\partial y_{i}^{*}}{\partial E_{i}} \mu_{i}^{*}>0$, the regulator should allocate permits so that $h_{i}^{\prime}>h_{j}^{\prime}$. The opposite occurs when firm $i^{\prime}$ s strategic effect is stronger than the one of firm $j$.

Note that, for firm $k$, the marginal profitability of receiving an additional permit to use in production is given by the savings in the marginal abatement cost $h_{k}^{\prime}$ plus the marginal profitability of the output increase that such permit will generate, that is entailed by strategic interaction and it is given by $\frac{\partial y_{k}^{*}}{\partial E_{k}} \mu_{k}^{*}$ in our set-up. Accordingly, an alternative approach to interpret the condition (11) is to state that the welfare maximizing permits' allocation must equalize firms' total marginal profitability of receiving an additional permit, as can be seen from restating (11) as

$$
h_{i}^{\prime}+\frac{\partial y_{i}^{*}}{\partial E_{i}} \mu_{i}^{*}=h_{j}^{\prime}+\frac{\partial y_{j}^{*}}{\partial E_{j}} \mu_{j}^{*}
$$

A regulator that considers strategic interaction in the output market is neglected would allocate permits so as to ensure equimarginality of abatement costs. For the sake of comparison let us note the equimarginal allocation rule as $\alpha^{E M}$, which solves: ${ }^{23}$

$$
\frac{\partial p_{j}}{\partial y_{i}} \frac{\partial y_{i}^{*}}{\partial E_{i}} y_{j}^{*}+\frac{\partial p_{i}}{\partial y_{j}} \frac{\partial y_{j}^{*}}{\partial E_{i}} y_{i}^{*}=\frac{S \alpha^{E M}-E_{i}^{*}(q)}{\partial E_{i}^{*}(q) / \partial q}
$$

Recall that the sign of the LHS of (12) is a priori undetermined. The term associated with firm $j^{\prime}$ s rising cost-effect, $\frac{\partial p_{j}}{\partial y_{i}} \frac{\partial y_{i}^{*}}{\partial E_{i}} y_{j}^{*}$, is negative, whereas the term associated with firm $i$ 's rising-cost effect, $\frac{\partial p_{i}}{\partial y_{j}} \frac{\partial y_{j}^{*}}{\partial E_{i}} y_{i}^{*}$, is positive. When the first term is dominant, so that $\frac{\partial p_{i}}{\partial y_{j}} \frac{\partial y_{j}^{*}}{\partial E_{i}} y_{i}^{*}<-\frac{\partial p_{j}}{\partial y_{i}} \frac{\partial y_{i}^{*}}{\partial E_{i}} y_{j}^{*}$, the LHS of (12) is negative. This takes place, when one or more of the following occurs: $\left|\frac{\partial p_{i}}{\partial y_{j}}\right|$ is sufficiently smaller than $\left|\frac{\partial p_{j}}{\partial y_{i}}\right|$; the equilibrium output of firm $i$ is lower than the equilibrium output of firm $j$, and/ or firm $i^{\prime} s$ abatement technology is significantly less efficient than the one of firm $j$. In this case, the equimarginal allocation rule distributes more permits to firm $i$ (recall that $\partial E_{i}^{*}(q) / \partial q$ is negative). By making firm $i$ a net-seller of permits, the regulator is inducing firm $j$ to buy permits in the market and therefore, firm $j$ will have additional incentives to mark-down the price of permits (this corresponds to the effect $\frac{x_{i}^{*}}{\partial E_{i}^{*} / \partial q}$, in equation (6)). This partially offsets the strength of firm $j$ 's rival's cost rising effect, restoring equimarginality of abatement. The opposite situation takes place when the strength of the rising rival's cost effect is higher for firm $i$ than for firm $j$ (which occurs, for example, when firm $i$ is endowed with a more efficient abatement

\footnotetext{
${ }^{23}$ To obtain condition (12), let us consider the results in the first and second stage of the game and substract equations such that $h_{i}^{\prime}\left(a_{i}^{*}\right)=h_{j}^{\prime}\left(a_{j}^{*}\right)$.
} 
technology). In that case the LHS of (12) is positive and equimarginality requires firm $j$ to be a net-seller of permits. By doing this, the regulator ensures that firm $j$ will set a positive mark-up on the price of permits, which countervails the strength of firm $i$ 's rival's rising cost effect.

In addition, our model also predicts that, everything else the same, the fraction of permits allocated to firm $i$ to ensure equimarginality tends to increase if this firm becomes more inefficient in relation to firm $j .^{24}$

Finally, it is worth noting that the allocation schemes $\alpha^{W E} \in[0,1]$ as well as $\alpha^{E M} \in[0,1]$ may not always exist in our set-up. In particular, the conditions for the existence of an interior solution to the regulator's problem may be violated when the degree of asymmetry between firms is very high in terms of abatement. Same thing with the equimarginal allocation: when the impossibility to restore equimarginality in abatement is caused by the asymmetry in abatement technologies, the regulator should allocate all the available emission permits to the firm with the highest marginal abatement $\operatorname{cost}^{25}$.

Optimal allocation rules may change considerably depending on the regulator's objective. Some examples of possible objectives to be pursued by the regulator are: equalization of abatement costs, maximization of joint profits, maximization of consumers' surplus (even with some preference over some category of consumers), maximization of total welfare, or other. Depending on the scope of the regulator's activity and the specific objective pursued by the regulator, there may be contradictory recommendations regarding the optimal allocation rule $\alpha^{*}$. In the following subsection, we rely on an example to study this point.

\subsection{The importance of output demand characteristics}

In this subsection we rely on a simulation ${ }^{26}$ to illustrate the policy implications of our model. In particular, we stress the importance of output demand characteristics in the definition of the optimal allocation rules by the environmental regulator. In line with the example presented in Appendix B, we consider an industry in which: (i) the inverse demand for good $k$ is given by $p_{k}\left(y_{k}, y_{-k}\right)=25+\varepsilon_{j}-2 y_{k}-\delta y_{-k}$, with $0<\delta<2$ and $\varepsilon_{j}=0.1$ if $k=j$; (ii) $c_{k}\left[y_{k}\right]=$ $\frac{\left(y_{k}\right)^{2}}{4}$; (iii) $\beta=0.8$; (iv) $S=3$, and, (v) firms' abatement technologies are given by $h_{i}\left(a_{i}\right)=$

$\frac{1.1\left(a_{i}\right)^{2}}{2}$ and $h_{j}\left(a_{j}\right)=\frac{\left(a_{j}\right)^{2}}{2}$. We compute optimal allocation rules for progressively higher degrees of substitutability between goods, comparing outcomes for $\delta=0.01 ; \delta=0.4 ; \delta=1.5$; and $\delta=1.99$. Concerning the impact of the objective pursued by the regulator, we compare optimal allocation

\footnotetext{
${ }^{24}$ For instance, in the context of the example presented in Appendix B, we would obtain that $\alpha^{E M}$ increases from $50 \%$ to $54.9 \%$ when $\theta$ increases from $\theta=1$ to $\theta=1.1$.

${ }^{25}$ For instance, in the context of the example presented in Appendix B, we obtain the following corner solutions: (i) $\alpha^{E M}=1$ when firm $i$ is endowed with the least efficient abatement technology $(\theta=4)$; and (ii) $\alpha^{E M}=0$ when firm $i$ is endowed with the most efficient technology $(\theta=0.4)$.

${ }^{26} \mathrm{In}$ fact it is hard to derive general policy implications in our framework since equilibrium outcomes are affected by several determinants (demand configuration, production costs, abatement technologies, pollution intensities and regulatory decisions) with potentially opposite effects.
} 
rules under four different regulatory objectives: (i) equimarginality of abatement effort (EM); (ii) maximization of firms' joint profits $(J P)$; and, finally, (iii) maximization of total social welfare $(W)$. To compute consumer's surplus, we use the partial equilibrium analysis from Belleflamme and Peitz (2010). Table 3 summarizes our results:

\begin{tabular}{llll} 
Substitution & EM & JP & W \\
\hline \hline$\delta=0.01$ & $\alpha_{E M}^{*}=54.1 \%$ & $\alpha_{J P}^{*}=54 \%$ & $\alpha_{W}^{*}=69 \%$ \\
$\delta=0.4$ & $\alpha_{E M}^{*}=54.4 \%$ & $\alpha_{J P}^{*}=53 \%$ & $\alpha_{W}^{*}=61 \%$ \\
$\delta=1.5$ & $\alpha_{E M}^{*}=54.9 \%$ & $\alpha_{J P}^{*}=51 \%$ & $\alpha_{W}^{*}=60 \%$ \\
$\delta=1.99$ & $\alpha_{E M}^{*}=55.2 \%$ & $\alpha_{J P}^{*}=51 \%$ & $\alpha_{W}^{*}=60 \%$ \\
\hline
\end{tabular}

Table 3: Optimal permits allocations

Reading each line separately, we conclude that the optimal allocation of permits varies according to the regulator's objective. When the regulator wants to promote equimarginality of pollution abatement (EM), he voluntarily chooses to ignore the impact of permits decisions on the output market. Table 3 shows that, under a equimarginality allocation rule, the regulator must allocate more permits to the firm that owns the less efficient abatement technology (as described in the previous section). In relation to the way output market characteristics influence the equimarginality allocation rule, table 3 shows that as substitutability decreases, rising-rival's cost strategies are weaker (due to less competition) and therefore the lower needs to be the compensation ${ }^{27}$ to the least efficient firm. It is worth noting that the equimarginality allocation rule is not very sensitive to changes in the degree of output substitutability. In fact output demands remain perfectly symmetric, with $\frac{\partial p_{i}}{\partial y_{j}}=\frac{\partial p_{j}}{\partial y_{i}}$ and therefore, the degree of product substitutability only affects the strength of rival's cost-rising effects indirectly, through its effect on output production (and therefore in firms' abatement needs).

Turning now to the maximization of joint profits (JP), the optimal allocation of permits once more favours the least efficient firm $i$. This is the case because, when giving more permits to the least efficient firm, the increase in its output production (and its profits) more than compensates the decrease in its rival's production (and profits). The changes in the profit-maximizing allocation as substitutability changes are stronger than in the cost-effective allocation.

Finally, the welfare maximizing $(\mathbf{W})$ allocation rule gives even more permits to the least efficient firm than the profit maximizing allocation rule. This is the case because the latter only accounts for the fact that the increase in the least efficient firm's output production after an increase in $\alpha$ more than compensates the decrease in the most efficient firm's output production. Instead, the welfare maximizing allocation rule also accounts for the fact that the mentioned changes in quantities affect prices and consequently consumer's surplus. In particular, for the values of the parameters that we

\footnotetext{
${ }^{27}$ Compensation in this context takes place through a higher permits allocation.
} 
considered, we observe that the reduction in the price $p_{i}^{*}$ more than compensates the increase in $p_{j}^{*}$. This leads to permits allocation rules more biased towards firm $i$ (around 60\%)

Concerning the impact of output substitutability on the welfare-maximizing allocation rule, we find that as goods become less substitutable, firm $i$ must receive a higher fraction of permits to compensate the fact that $p_{i}^{*}$ is higher than $p_{j}^{*}$ (due to the higher marginal abatement costs of firm i).

It is worth noting that the amount of permits allocated to the least efficient firm increases as we move rightwise in Table 3. This is because, when giving more permits to the least efficient firm, the cost-effective allocation rule takes into account the benefit in terms of cost minimization while the profit-maximizing allocation takes into account, additionally, the positive effect on overall output quantity and, finally, the welfare-maximizing allocation considers the benefits for consumers in terms of prices (although one group of consumers is favoured in detriment of the other). ${ }^{28}$

\section{CONCLUDING REMARKS}

We have shown how the possibility of the simultaneous adoption of rival's cost-rising strategies in an oligopolistic market may either aggravate of ameliorate the cost-effectiveness of environmental regulation based on TEP markets. In particular, we found that it depends on each firms' position as buyer or seller of permits as well as on the interplay of abatement and production cost structures (and its impact in the output market with differentiated products). In light of the previous results, we have investigated optimal criteria to allocate permits between firms as a function of the regulator's objective, addressing in more detail the characterization of permits allocation that lead to cost-effectiveness of pollution abatement. We find that the optimal allocation of permits is the one that ensures that the difference on each firm's price-cost margins in the permits and in the output market are equalized for the last permit distributed. Our analysis also reveals that optimal allocation rules may be extremely sensitive to the specific characteristics of the output market. Then, in line with Sartzetakis (1997), this paper emphasizes that the regulator is often faced with extremely demanding information needs.

\footnotetext{
${ }^{28}$ The analysis regarding the regulatory possibilities as a function of goods substitutability becomes particularly relevant in the case of environmental policies that may affect the redistribution of production between goods and, through that redistribution, harm a specific group of consumers (in the case of our example, those would be the consumers of good $j$ ).
} 


\section{REFERENCES}

[1] Belleflamme, P and Peitz, M. [2010] Industrial Organization Markets and Strategies, Cambridge University Press.

[2] Amir, R. [2005]. Supermodularity and Complementarity in Economics: An Elementary Survey, Southern Economic Journal, 71(3), 636-660.

[3] Chen, Y., Hobbs, B.F., Leyffer, S. and Munson T.S., [2006], Leader-follower equilibria for electric power and NOx allowances markets, Computational Managment Science, 3, 307-330.

[4] G. de Feo, J. Resende, M-E Sanin, [2012], Emission permits trading and downstream strategic interaction, forthcoming The Manchester School.

[5] D. M. D. Eshel, [2005], Optimal allocation of tradable pollution rights and market structures, Journal of Regulatory Economics, 28:2, 205-223.

[6] Fehr, N.-H. M. v. d. [1993], Tradable Emission Rights and Strategic Interaction, Environmental and Resource Economics, 3, 129-151.

[7] Hahn, R. [1985], Market power and transferable property rights. Quarterly Journal of Economics, 99, 753-765.

[8] IPCC [1990], Climate change: The IPCC Scientific Assessment.

[9] Kolstad, J. and F. Wolak, [2008], Using emission permits prices to rise electricity prices: Evidence from the California electricity market, Harvard University, mimeo.

[10] Liski, M and Juan-Pablo Montero, [2011], Market Power in an Exhaustible Resource Market: The Case of Storable Pollution Permits, Economic Journal, 121(551), 116-144.

[11] Misiolek, W. S. and H. W. Elder [1989], Exclusionary manipulation of markets of pollution rights. Journal of Environmental Economics and Management, 16, 156-166.

[12] Montero, J.P. [2009], Market Power in Pollution Permit Markets. The Energy Journal, 30 (Special I), 115-142.

[13] Montgomery, D. W. [1972], Market in Licenses and Efficient Pollution Control Programs, Journal of Economic Theory, 395-418.

[14] Requate, T. [2005]. Timing and Commitment of Environmental Policy, Adoption of New Technology, and Repercussions on R\&D, Environmental \& Resource Economics, 31(2), 175-199, 06. 
[15] Salop, S.C. and D.T. Scheffman [1983], Raising rivals' costs, American Economic Review Papers and Proceedings, 73, 267-271.

[16] Sartzetakis E.S. [1997], Tradable Emission Permits Regulations in the Presence of Imperfectly Competitive Product Markets: Welfare Implications, Environmental and Resource Economics, 9, 65-81.

[17] Tanaka, M. and Y. Chen [2012], Emissions Trading in Forward and Spot Markets of Electricity, The Energy Journal, 33(2)

[18] Wolak, F.A. [2003b], Measuring Unilateral Market Power in Wholesale Electricity Markets: The California Market 1998 to 2000, American Economic Review, May, 425-430. 


\section{Appendix A}

\section{Proof of Lemma 1}

By applying the theory of supermodular games, the sign of the effect of $E_{k}$ on $y_{k}$ and $y_{-k}$ depends on the sign of the cross-partial derivatives $\frac{\partial^{2} \Pi_{k}}{\partial y_{k} \partial E_{k}}$ and $\frac{\partial^{2} \Pi_{-k}}{\partial y_{-k} \partial E_{k}} \cdot{ }^{29} \quad$ Without loss of generality, suppose $k=i$. Since

$$
\frac{\partial^{2} \Pi_{i}}{\partial y_{i} \partial E_{i}}=\beta h_{i}^{\prime \prime}\left(\beta y_{i}-E_{i}\right)>0
$$

and

$$
\frac{\partial^{2} \Pi_{j}}{\partial y_{j} \partial E_{i}}=-\beta h_{j}^{\prime \prime}\left(\beta y_{j}-S+E_{i}\right)<0
$$

the larger $E_{i}$, the larger $y_{i}^{*}\left(E_{i}\right)$ and the smaller $y_{j}^{*}\left(E_{i}\right)$.

\section{SOC of the second-stage optimization problem}

The second order condition of the problem can be written as

$$
\frac{d^{2} \Pi_{i}}{d E_{i}^{2}}=\frac{\partial\left(d \Pi_{i} / d E_{i}\right)}{\partial E_{i}}+\frac{\partial\left(d \Pi_{i} / d E_{i}\right)}{\partial y_{i}^{\star}} \frac{\partial y_{i}^{\star}}{\partial E_{i}}+\frac{\partial\left(d \Pi_{i} / d E_{i}\right)}{\partial y_{j}^{\star}} \frac{\partial y_{j}^{\star}}{\partial E_{i}}
$$

where the first term is:

$$
\frac{\partial\left(d \Pi_{i} / d E_{i}\right)}{\partial E_{i}}=\left(\frac{\partial y_{i}^{\star}}{\partial E_{i}}-1\right) h_{i}^{\prime \prime}\left(\beta y_{i}^{\star}-E_{i}\right)+\frac{\partial P_{i}\left(y_{i}^{\star}, y_{j}^{\star}\right)}{\partial y_{j}^{\star}} \frac{\partial y_{j}^{\star}}{\partial E_{i}}
$$

the second term is:

$$
\frac{\partial\left(d \Pi_{i} / d E_{i}\right)}{\partial y_{i}^{\star}} \frac{\partial y_{i}^{\star}}{\partial E_{i}}=\left[\beta h_{i}^{\prime \prime}\left(\beta y_{i}^{\star}-E_{i}\right)+2 \frac{\partial p_{i}\left(y_{i}^{\star}, y_{j}^{\star}\right)}{\partial y_{i}^{\star}}-c_{i}^{\prime \prime}\left(y_{i}^{\star}\right)-\beta^{2} h_{i}^{\prime \prime}\left(\beta y_{i}^{\star}-E_{i}\right)\right] \frac{\partial y_{i}^{\star}}{\partial E_{i}}
$$

and finally the third term is:

$$
\frac{\partial\left(d \Pi_{i} / d E_{i}\right)}{\partial y_{j}^{\star}} \frac{\partial y_{j}^{\star}}{\partial E_{i}}=\frac{\partial p_{i}\left(y_{i}^{\star}, y_{j}^{\star}\right)}{\partial y_{i}^{\star}} \frac{\partial y_{i}^{\star}}{\partial E_{i}} \frac{\partial y_{i}^{\star}}{\partial E_{i}}
$$

Therefore the SOC can be written as follows:

$$
\left[\left(1-\beta^{2}+\beta\right) \frac{\partial y_{i}^{\star}}{\partial E_{i}}-1\right] h_{i}^{\prime \prime}\left(\beta y_{i}^{\star}-E_{i}\right)+\frac{\partial p_{i}\left(y_{i}^{\star}, y_{j}^{\star}\right)}{\partial y_{i}^{\star}} \frac{\partial y_{i}^{\star}}{\partial E_{i}}\left(1+\frac{\partial y_{i}^{\star}}{\partial E_{i}}\right)+\left[2 \frac{\partial p_{i}\left(y_{i}^{\star}, y_{j}^{\star}\right)}{\partial y_{i}^{\star}}-c_{i}^{\prime \prime}\left(y_{i}^{\star}\right)\right] \frac{\partial y_{i}^{\star}}{\partial E_{i}}<0
$$

\section{Proof of (8)}

\footnotetext{
${ }^{29}$ See Amir (2005) for a survey of this approach.
} 
Applying the chain rule, the derivatives $\frac{\partial y_{k}^{*}}{\partial \alpha}$ can be decomposed as follows:

$$
\frac{\partial y_{k}^{*}}{\partial \alpha}=\frac{\partial y_{k}^{*}\left(q, E_{i}\right)}{\partial E_{i}} \frac{\partial E_{i}^{*}(q)}{\partial q} \frac{\partial q^{*}}{\partial \alpha}
$$

where the derivatives $\frac{\partial y_{k}^{*}\left(q, E_{i}\right)}{\partial E_{i}}$ have already been obtained in Lemma, with $\frac{\partial y_{k}^{*}\left(E_{k}\right)}{\partial E_{k}}>0$; and $\frac{\partial y_{-k}^{*}\left(E_{k}\right)}{\partial E_{k}}<0$. We have also seen that $\frac{\partial E_{i}^{*}}{\partial q}<0$ because $\frac{\partial^{2} \Pi_{i}}{\partial E_{i} \partial q}<0$. Similarly, $\frac{\partial q^{*}}{\partial \alpha}<0$ because $\frac{\partial^{2} \Pi_{j}}{\partial q \partial \alpha}<0$ (complementarity and supermodularity, see Amir, 2005).

Accordingly, along the equilibrium path

$$
\frac{\partial y_{i}^{*}}{\partial \alpha}=\frac{\partial y_{i}^{*}\left(q, E_{i}\right)}{\partial E_{i}} \frac{\partial E_{i}^{*}(q)}{\partial q} \frac{\partial q^{*}}{\partial \alpha}>0
$$

and

$$
\frac{\partial y_{j}^{*}}{\partial \alpha}=\frac{\partial y_{i}^{*}\left(q, E_{i}\right)}{\partial E_{i}} \frac{\partial E_{i}^{*}(q)}{\partial q} \frac{\partial q^{*}}{\partial \alpha}<0 .
$$

As stated in (8) after a marginal variation of $\alpha$, the equilibrium output of firm $i$ changes in the same direction, while the equilibrium output of firm $j$ changes in the opposite direction.

\section{Appendix B: an example}

Herein we rely on an example to illustrate how relevant parameters, such as firms' relative efficiency in terms of abatement, may affect equilibrium market outcomes. ${ }^{30}$ We consider that (i) the inverse demand for good $k$ is given by $p_{k}\left(y_{k}, y_{-k}\right)=25-2 y_{k}-1.5 y_{-k}$; (ii) firms' production technology is similar, with $c_{k}\left[y_{k}\right]=\frac{\left(y_{k}\right)^{2}}{4}$; (iii) the intensity of pollution is equal to $\beta=0.8$; (iv) the total stock of emission permits is exogenously fixed by the regulator to meet the pollution control target and we consider it to be $S=3$, which constrains firms' production plans. Finally, ( $v$ ) firms' abatement technologies are given by $h_{i}\left(a_{i}\right)=\frac{\theta\left(a_{i}\right)^{2}}{2}$ and $h_{j}\left(a_{j}\right)=\frac{\left(a_{j}\right)^{2}}{2}$.

In what follows, we compute the equilibrium outcomes as in Section 2.1 considering the specific functions detailed in points (i) to (v). Regarding firm $i^{\prime}$ s abatement technology, we consider three possible scenarios: firm $i$ is more efficient in terms of abatement $(\theta=0.4)$; firms have symmetric abatement technologies $(\theta=1)$; and firm $j$ is more efficient in terms of abatement $(\theta=4)$. In the following table we reproduce the predictions of our model regarding equilibrium prices (both for

\footnotetext{
${ }^{30}$ Note that a similar analysis could be performed to study the influence of other parameters, such as output demand, production costs or the pollution cap $S$. For the sake of simplicity, in the paper we present only an example that analyses the effects of abatement technologies and, at the end of the section, we comment on other potentially relevant parameters.
} 
permits and output) and equilibrium trading levels for different values of $\alpha$.

\begin{tabular}{lcccc}
\hline & $p_{i}^{*}$ & $p_{j}^{*}$ & $q^{*}$ & $x_{i}^{*}$ \\
\hline \hline$\theta=0.4$ & $10.9+0.02 \alpha$ & $10.9+0.13 \alpha$ & $2.1-0.21 \alpha$ & $2.3 \alpha-0.9$ \\
$\theta=1$ & $11.2-0.11 \alpha$ & $11.2-0.11 \alpha$ & $3.3-0.75 \alpha$ & $2.0 \alpha-1.0$ \\
$\theta=4$ & $12.4-0.78 \alpha$ & $11.8-0.22 \alpha$ & $7.1-2.81 \alpha$ & $1.7 \alpha-1.1$ \\
\hline
\end{tabular}

Table B: Equilibrium outcomes $\theta=0.4 ; \theta=1 ; \theta=4$

Table B shows that equilibrium output prices depend on firms' abatement technologies. As we would expect, since firms are symmetric with respect to everything else except abatement efficiency, the firm with the most efficient abatement technology has a competitive advantage in the output market offering its product as a lower price. Furthermore, Table B shows that an increase in $\theta$ leads to an increase in the output price of both goods. The regulator can partially offset this increase by allocating more permits to firm $i$ when this firm becomes progressively more inefficient. In a quite different context Tanaka and Chen (2012) find a contrasting result, which underlines the importance of taking into account the market structure as a key variable to choose optimal permits allocation.

Regarding permits' trading, Table B shows that firm $i$ might be a net buyer or seller, depending on the value of $\alpha$. For example, if $\alpha<0.39$, firm $i$ is always a net buyer of permits, for the three technological specifications. In contrast, if $\alpha>0.65$, firm $i$ is always a net seller of permits, for the three technological specifications. For intermediate values of $\alpha$, firm $i$ is a net seller only for some specifications of the abatement cost function. As expected, when firm $i$ becomes relatively less efficient than firm $j$, it sells less (or buys more) permits to compensate its lower abatement efficiency and become more competitive in the output market (in other words, firm $i$ is adopting a rival's rising-cost strategy). In what concerns the price of permits, when firm $i$ becomes relatively less efficient than firm $j$, Table B shows an increase in the price of permits. As we move from $\theta=0.4$ to $\theta=4$, and firm $i$ becomes more inefficient, firm $j$ increases the price of permits to withhold permit emissions and avoid the effects of firm $i^{\prime}$ s rival's rising-cost strategies in the second stage. It is worth noting that herein we just consider technological specifications for which $q^{*}-\left(h_{j}^{\prime}\right)^{*}>0$, meaning that even when firm $j$ is a net buyer of permits, the rival's rising cost effect is always dominant.

\section{Appendix C: Social Optimum}

The regulator's problem is to maximize (assuming a linear damage function $a S$ ) $W=C S+$ $\Pi_{i}+\Pi_{j}-a S$ with respect to $\alpha$. Whenever interiority conditions are met, the FOC to the previous problem is given by $\frac{\partial C S}{\partial \alpha}+\frac{\partial \Pi_{i}}{\partial \alpha}+\frac{\partial \Pi_{j}}{\partial \alpha}=0$. Let us now compute each of the derivatives herein.

\section{Consumer Surplus}


Let us call direct and indirect effects as $\frac{\partial p_{i}}{\partial y_{i}}=\frac{\partial p_{j}}{\partial y_{j}}=-\gamma$ and $\frac{\partial p_{i}}{\partial y_{j}}=\frac{\partial p_{j}}{\partial y_{i}}=-\delta$. The consumer surplus for symmetric linear demands and differentiated products is given by (see Belleflamme and Peitz, 2010 for details):

$$
C S=\frac{1}{2}\left(\gamma y_{i}^{2}+2 \delta y_{i} y_{j}+\gamma y_{j}^{2}\right)
$$

Deriving w.r.t. $\alpha$ and equalizing to zero we get, after rearraning,

$$
\frac{\partial E_{i}^{*}}{\partial q} \frac{\partial q^{*}}{\partial \alpha}\left(\gamma\left(\frac{\partial y_{i}^{*}}{\partial E_{i}} y_{i}^{*}+\frac{\partial y_{j}^{*}}{\partial E_{i}} y_{j}^{*}\right)+\delta\left(\frac{\partial y_{i}^{*}}{\partial E_{i}} y_{j}^{*}+\frac{\partial y_{j}^{*}}{\partial E_{i}} y_{i}^{*}\right)\right)=0
$$

\section{Profits}

We maximize profits w.r.t. $\alpha$ and we get:

$$
\begin{aligned}
\frac{\partial \Pi_{i}}{\partial \alpha}= & \frac{d y_{i}^{*}}{d \alpha}\left(-\gamma y_{i}+p_{i}^{*}-c^{\prime}\left(y_{i}^{*}\right)-\beta h_{i}^{\prime}\right) \\
& -\delta \frac{d y_{j}^{*}}{d \alpha} y_{i}+\frac{d q^{*}}{d \alpha}\left(\alpha S-E_{i}\right) \\
& +q^{*}\left(S-\frac{d E_{i}^{*}}{d \alpha}\right)-h_{i}^{\prime}\left(-\frac{d E_{i}^{*}}{d \alpha}\right)
\end{aligned}
$$

By the FOC of the third stage, we have $\left(-\gamma y_{i}+p_{i}^{*}-c^{\prime}\left(y_{i}^{*}\right)-\beta h_{i}^{\prime}\right)=0$.

Thus, by analogy, we should obtain that

$$
\frac{\partial \Pi_{j}}{\partial \alpha}=-\delta \frac{d y_{i}^{*}}{d \alpha} y_{j}-\frac{d q^{*}}{d \alpha}\left(\alpha S-E_{i}\right)-q^{*} S+\left(q-h_{j}^{\prime}\right) \frac{d E_{i}^{*}}{d \alpha}
$$

Adding up so that we have the effect of $\alpha$ on total profits, we obtain:

$$
\frac{\partial \Pi_{i}}{\partial \alpha}+\frac{\partial \Pi_{j}}{\partial \alpha}=-\delta\left(\frac{d y_{j}^{*}}{d \alpha} y_{i}+\frac{d y_{i}^{*}}{d \alpha} y_{j}\right)+\left(h_{i}^{\prime}-h_{j}^{\prime}\right) \frac{d E_{i}^{*}}{d \alpha}
$$

\section{Effect of $\alpha$ on total welfare}

Then, adding up previous derivations we find that $\frac{\partial C S}{\partial \alpha}+\frac{\partial \Pi_{i}}{\partial \alpha}+\frac{\partial \Pi_{j}}{\partial \alpha}=0$ if and only if

$$
\gamma\left(\frac{d y_{i}^{*}}{d \alpha} y_{i}^{*}+\frac{d y_{j}^{*}}{d \alpha} y_{j}^{*}\right)+\left(h_{i}^{\prime}-h_{j}^{\prime}\right)\left(\frac{d E_{i}^{*}}{d \alpha}\right)=0
$$

that after developing becomes

$$
\frac{d E_{i}^{*}}{d \alpha}\left(\gamma\left(\frac{\partial y_{i}^{*}}{\partial E_{i}} y_{i}^{*}+\frac{\partial y_{j}^{*}}{\partial E_{i}} y_{j}^{*}\right)+h_{i}^{\prime}-h_{j}^{\prime}\right)=0
$$


Considering that $\frac{\partial p_{i}}{\partial y_{i}}=\frac{\partial p_{j}}{\partial y_{j}}=-\gamma$ we get equation (9):

$$
\frac{d E_{i}^{*}}{d \alpha}\left(h_{i}^{\prime}-h_{j}^{\prime}\right)=\frac{d E_{i}^{*}}{d \alpha}\left(\frac{\partial y_{i}^{*}}{\partial E_{i}} y_{i}^{*} \frac{\partial p_{i}}{\partial y_{i}}+\frac{\partial y_{j}^{*}}{\partial E_{i}} y_{j}^{*} \frac{\partial p_{j}}{\partial y_{j}}\right) .
$$

The previous can be rearranged considering the following equalities taken from the third stage equilibrium:

$$
\begin{aligned}
y_{i}^{*} \frac{\partial p_{i}}{\partial y_{i}} & =-\left(p_{i}^{*}-c_{i}^{\prime}-\beta h_{i}^{\prime}\right) \\
y_{j}^{*} \frac{\partial p_{i}}{\partial y_{i}} & =-\left(p_{j}^{*}-c_{j}^{\prime}-\beta h_{j}^{\prime}\right)
\end{aligned}
$$

to get

$$
\frac{d E_{i}^{*}}{d \alpha}\left(h_{i}^{\prime}-h_{j}^{\prime}\right)=\frac{d E_{i}^{*}}{d \alpha}\left(-\frac{\partial y_{j}^{*}}{\partial E_{i}}\left(p_{j}^{*}-c_{j}^{\prime}-\beta h_{j}^{\prime}\right)-\frac{\partial y_{i}^{*}}{\partial E_{i}}\left(p_{i}^{*}-c_{i}^{\prime}-\beta h_{i}^{\prime}\right)\right)
$$

Adding and subtracting $q \frac{d E_{i}^{*}}{d \alpha}$ on the LHS and rearranging, we get

$$
\left[\left(q-h_{j}^{\prime}\right)-\frac{\partial y_{j}^{*}}{\partial E_{j}} \mu_{j}^{*}\right] \frac{d E_{i}^{*}}{d \alpha}=\left[\left(q-h_{i}^{\prime}\right)-\frac{\partial y_{i}^{*}}{\partial E_{i}} \mu_{i}^{*}\right] \frac{d E_{i}^{*}}{d \alpha}
$$

where we note markups as $\mu_{j}^{*}=\left(p_{j}^{*}-c_{j}^{\prime}-\beta h_{j}^{\prime}\right)$ and $\mu_{i}^{*}=\left(p_{i}^{*}-c_{i}^{\prime}-\beta h_{i}^{\prime}\right)$ respectively. 